\title{
Examining Behaviors Using Respondents' Cell Phones and a Burst Design: Drinking and Activities Across the First Year of College Among Transitioning Freshmen
}

\author{
Amy L. Anderson ${ }^{1}$ - Samantha S. Clinkinbeard ${ }^{2}$. \\ Timothy C. Barnum ${ }^{3}$ - Rita J. Augustyn ${ }^{3}$
}

Received: 31 August 2015 /Revised: 17 January 2016 / Accepted: 5 February 2016 /

Published online: 23 February 2016

(C) Springer International Publishing AG 2016

\begin{abstract}
Purpose The study of developmental and life-course changes of an individual necessitates longitudinal data. Traditional panel designs, however, that tend to collect data annually or less often may not reflect change experienced by individuals especially in periods of transition. The first year of college likely is one such period in which change takes place at a rapid pace.

Methods We followed approximately 100 residential college students across their freshman year. In an attempt to capture the changes taking place in friendships, activities, and alcohol use, we used a traditional panel design in which we administered structured surveys at the beginning, middle, and end of the academic year. We extended
\end{abstract}

Electronic supplementary material The online version of this article (doi:10.1007/s40865-016-0027-4) contains supplementary material, which is available to authorized users.

Amy L. Anderson

amyanderson@unomaha.edu

Samantha S. Clinkinbeard

sclinkinbeard@unomaha.edu

Timothy C. Barnum

tbarnum@unomaha.edu

Rita J. Augustyn

raugustyn@unomaha.edu

1 School of Criminology and Criminal Justice, 310 Nebraska Hall, Lincoln, NE 68588-0561, USA

2 School of Criminology and Criminal Justice, 6001 Dodge Street, 218 CPACS, Omaha, NE 68182-0149, USA

3 School of Criminology and Criminal Justice, University of Nebraska at Omaha, 6001 Dodge Street, CPACS 218, Omaha, NE 68182, USA 
this design by employing a "burst" design to capture data frequently and in real time. Respondents were sent a text message with a link to a short survey asking about their activities. They received our text across 3-day intervals, multiple times within each day, approximately every month of the school year.

Results In this paper, we discuss our approach and demonstrate the utility of burst designs. We show how such data collection schemes can complement more traditional designs by comparing information collected with the two approaches to show what could have been lost had we relied only on surveys at three time points.

Conclusions The developmental transitions of college students occurred at a faster rate than our panel design could capture. Our findings suggest that researchers interested in a wide variety of transitions should employ burst designs alongside other traditional data collection techniques.

Keywords Burst designs · College drinking · Cell phone surveys · Developmental · Criminology

A hallmark of developmental research is the focus on various transitions throughout the life course. Transitions represent phases of rapid change in an individual's life. Successful navigation during these periods can have a significant impact on an individuals' short- and long-term trajectory. Transitions can occur due to developmental changes or can be brought about by significant life events such as a marriage or the birth of a child. Developmental growth periods may involve physical and hormonal changes, cognitive shifts or advances (e.g., transition from concrete to abstract thinking), emotional and identity exploration and change, and shifts in personal importance of contributors to the self-concept (e.g., growing importance of friends over parents, more focus on integrating sex roles into the self) [1-5]. Each transitional period brings its own unique focal points, though they are all marked by significant changes in an individual's life.

Transitions are important because new opportunities can alter beliefs, attitudes, and behaviors, potentially leading to turning points in the life course trajectory in a short period of time [6]. From a research perspective, however, the detection of changes in behavior that occur over the short term can be complicated. In this paper, we used data collected from a pilot study with a three-wave panel design that was supplemented by a more frequent ESM. We use measures related to the activities and drinking patterns of college freshmen over their first academic year to address two research questions. First, do productive activities decline across the school year? Second, does drinking increase steadily across the year (i.e., linear function of time)?

The second aim of this paper is to examine the utility of a hybrid design. To accomplish this goal, we ask two additional questions related to our research design. First, do we get comparable estimates from a three-wave panel design and the ESM? Second, do we get similar estimates of the percentage of students drinking in college between our two data collection methods, with different respondents and different questions? We conclude by arguing that a similar methodological approach, particularly the burst design features, could be beneficial to researchers in criminology and criminal justice. 


\section{Background}

An important transition point for many young adults is the transition to college. While most youth experience varying levels of parental independence during the middle and high school years [7, 8], the most significant shift in independence happens as they transition out of high school and into the spheres of higher education and/or work [9]. Many youth move out of their parents' homes effectively limiting the amount of daily monitoring and guidance. Even for youth who do not move out of the home right after high school, parents may decide to relax rules and standards. The increase in independence translates to an increase in individual responsibility and accountability. Youth who transition to college become responsible for the organization of their day, often for the first time having complete control over their daily schedules and activities.

The transition to independence associated with entering college also brings with it exposure to a variety of recreational activities. Youth who begin college often find an increase in their exposure to drugs and alcohol as a result of a number of factors, such as the lack of parental monitoring and curfews, the increase in affiliation with peers of legal drinking (and purchasing) age, and lax social norms in the college environment [10-13]. Importantly, the increased access to substances that accompanies attending college comes at a time in life before youth have fully developed their cognitive and executive functioning capacity [14]. For example, recent research indicates that the frontal lobe, the area of the brain responsible for recognizing the potential consequences of behavior, does not fully develop until the mid-20s [15]. Thus, most college students experience this transition at a time when they are still maturing and decisionmaking abilities are still developing. The negative consequences that are sometimes associated with engaging in deviant behaviors on college campuses compel programmatic approaches and responses to these behaviors. As such, the adjustment to college is important to a variety of people, including the youth, their family and friends, and college administrators.

While there is evidence that drinking habits may be established during the freshman year [16], it is unclear how quickly this transition occurs. This developmental change may happen gradually over the course of the year or rapidly in the first few weeks or months of the transition to college. Additionally, little is known about college freshmen's activity habits and how this relates with their drinking behaviors. College freshmen may begin the year by engaging in largely productive activities and then shift to other activities as they become familiar with the college environment. While this idea has been largely unexplored, research has demonstrated that youth who spend a disproportionate amount of time in unstructured activities are at a higher risk for engaging in deviant behavior than youth who participate in structured or productive activities [17]. Further, spending more time in productive activities in the presence of capable guardians, such as sports, music, or study groups, is associated with increases in prosocial outcomes and decreases in substance abuse $[18,19]$.

On a related note, it was unclear the degree to which our traditional three-wave panel design provided the same information as our more intensive design that collected data frequently and in real time. As such, we also were interested in whether our conclusions regarding the transition to college (i.e., activities and drinking) across the first academic year were fairly consistent between our two data collection methods. The efficiency of the distribution of school resources directed at prosocial college behaviors would be 
improved if the timing of activities associated with adjustment could be identified. While traditional panel designs can detect change from one year to the next or even from one semester to the next, they are unlikely to determine when significant bursts of change occur. In order to capture change that can happen quickly or often, multiple data points over short periods of time are needed. In the next section, we review measurement burst designs, which we used in conjunction with the panel design to capture information about behaviors associated with the transition to college.

\section{Measurement-Burst Designs}

Researchers typically use a few types of longitudinal designs to measure developmental change. Changes that are expected to take place over a longer period of time are often measured over intervals of months or years using repeated measures. The larger the sample, however, the harder it becomes to collect data at shortly spaced intervals whether collected through surveys or interviews. A panel design with many data points is costly and time intensive, which means that the number of collection points is dependent on the amount of time and money available to the researchers for the project. As a result of this and other difficulties, there are generally only a few waves of data collected. If a researcher can only collect data at two or three points in time, then this also limits the ability to detect how quickly changes are happening.

Researchers interested in short-term intra- and inter-individual change sometimes use experience sampling methods (ESM). For example, Larson and various colleagues (e.g., [20,21]) used ESM to examine the activities of children and adolescents. The respondents in these studies carried electronic pagers and, when signaled, were asked to write down what they were doing in a booklet that was provided to them [22]. ESMs led to development of ecological momentary assessments (EMA), which have many benefits. Unlike most typical panel designs, EMA allows for multiple assessments of a construct across a short period of time [23]. Additionally, researchers can collect data from respondents without the problem of recall or keeping diaries over longer periods of time that need to be physically collected by the research team. Finally, some types of confounding can be reduced through the implementation of EMA due to a better sequencing of causal ordering as well as allowing for every individual to serve as their own control [24].

A measurement-burst design is a multilayered approach that combines EMA with a typical panel design. This design includes repeated measures that are collected over longer periods of time as well as repeated, intensive assessments collected daily or momentarily [25]. Nesselroade first used the term burst when he argued that to assess "intraindividual variability, longitudinal research designs need to be planned around successive 'bursts' of measurements rather than merely successive measurements" ([23], p. 235). Due to the intensive data collection, burst designs capture intraindividual variability in a way that repeated measurements spaced over months or years cannot. A key benefit of this design is increased stability in the variance estimations both between and within waves $[25,26]$. An individual's behaviors and psychological state can fluctuate within any given day as well as over time. Burst designs can help researchers distinguish fluctuating "state" dynamics from the more stable intra-individual traits [23]. 
Researchers have put burst designs into practice in a variety of ways. For example, Hedeker and Mermelstein [26] collected longitudinal data on adolescent smoking at baseline, 6 months, and 12 months. Included at each collection point was a self-report questionnaire and a time/event collection that lasted for 7 days. The researchers used EMA, where the respondents used hand-held computers to respond to prompts to complete a survey or to self-prompt a survey after he or she smoked a cigarette. Patrick, Maggs, and Lefkowitz [27] examined college drinking and sexual behaviors using burst data collected using Web-based surveys that were filled out for 14 consecutive days across seven semesters. Cullum and colleagues [28] collected daily drinking data from college students for 30 days, once a year for four consecutive years using Web-based surveys. The collection of daily experiences data can differ in the way respondents know when to respond (i.e., event-contingent, time-contingent, or signal-contingent) as well as how they record their responses (e.g., paper, computers).

\section{Our Study}

We used a prospective measurement-burst design where we combined a multiwave panel design with multiple bursts of EMA [23, 25] and collected information related to the activities and drinking patterns of college freshmen over their first academic year. In this paper, we used data collected from both components of our design to address two research questions. First, do productive activities decline across the school year? Second, does drinking increase steadily across the year (i.e., linear function of time)?

Aside from the substantive contribution, our data allow us to examine the methodological contributions of our hybrid data collection approach. As such, we addressed two additional questions that are related to our substantive questions above. First, do we get comparable estimates from a three-wave panel design as we do from the ESM? Second, do we get similar estimates of the percentage of students drinking in college between our different sources? Drinking is an illegal activity that youth are asked to recall in a typical panel study, but it may be hard to detect an increase or decrease in the probability of drinking between waves with such a design. Our hybrid design allows us to examine this possibility. Although EMA/ESM techniques have been used in other disciplines, they are under-utilized in the areas of criminology and criminal justice. We add to the literature in this area by showing how burst designs can complement traditional panel designs common in criminology and criminal justice and demonstrating that mobile and text messaging technology can be a useful way to capture this kind of data.

\section{Method}

\section{Sample}

Our sampling frame consisted of 922 freshmen that planned to live in on-campus housing. We sent letters to a random sample of 200 incoming students about 1 month before the start of fall semester and asked participants to return their signed consent 
forms via US mail. ${ }^{1}$ Several weeks later, we sent an email to another 83 randomly selected incoming students notifying them that they had been selected for participation and that we would be available during move-in days for them to complete consent forms. ${ }^{2}$ We made contact with students who had not returned a consent form during move-in weekend as they checked in for their keys and room assignments during the normal hours made available to students. In total, we received consent forms from 106 of the original 283 students (approximately $37 \%$ response rate), in addition to a convenience sample of 31 students. ${ }^{3}$ In total, we had 137 residential students complete a consent form although 12 never completed any study component, reducing the sample size to 125 respondents. ${ }^{4}$ Of those respondents, 105 completed the first inperson interview, which represents approximately $11 \%$ of the residential (i.e., campus housing) freshman population. Eight respondents who did not complete the in-person survey did contribute data in the cell phone components, while some respondents who completed the intake and/or in-person survey did not contribute any cell phone surveys. We had 100 respondents who contributed data through the cell phone component in addition to at least one of the three larger structured surveys. ${ }^{5}$

\section{Design Components}

We used data collected on the activities of college freshman to answer our research questions. Our overall study design consisted of intensive, multi-method tracking of a small cohort of incoming, residential freshmen over the course of their first year in college. We collected data through in-person structured and semi-structured interviews, traditional online structured surveys, mini-surveys completed via smartphones (i.e., experience sampling), and content analysis of Facebook and other social media user activity (see Table 1). We focus on the cell phone surveys and the structured interviews/ surveys in this paper, both of which are discussed in more detail below.

\section{Structured Interviews/Surveys}

We asked participants to complete a short online intake survey and an in-person interview that was approximately $1 \mathrm{~h}$ in length over the first few weeks of fall semester. Both the survey and interview were structured and were intended to collect baseline information on a variety of topics, including high school experiences, attitudes and

\footnotetext{
${ }^{1}$ We used SPSS to generate a random sample from the full list of incoming freshman with residential contracts.

${ }^{2}$ An additional 120 names were randomly selected from the full list, and after cleaning we contacted the 83 remaining unique respondents with complete data.

${ }^{3}$ Some of these students asked to participate during move-in even though they were not on the recruitment list while the others responded to a single participant recruitment email sent to on-campus freshmen at the start of the semester intended to increase the sample size.

${ }^{4}$ Challenges to recruitment included both late grant notification and an age of consent set at 19 . There were freshman who communicated to us in person or through email that they would have participated but did not due to the extra work associated with obtaining parental consent (e.g., out-of-state). Males were harder to recruit than females, and of those who completed the first interview, approximately $75 \%$ were female and ranged in age from 17 to $24(M=18.27, S D=0.86)$.

${ }^{5}$ The average age of our final sample on the first day of the interviews in August was 18.71 (range of 17.8724.34) and was 19.39 (range of 18.56-25.02) on the second day of burst 7 in May.
} 


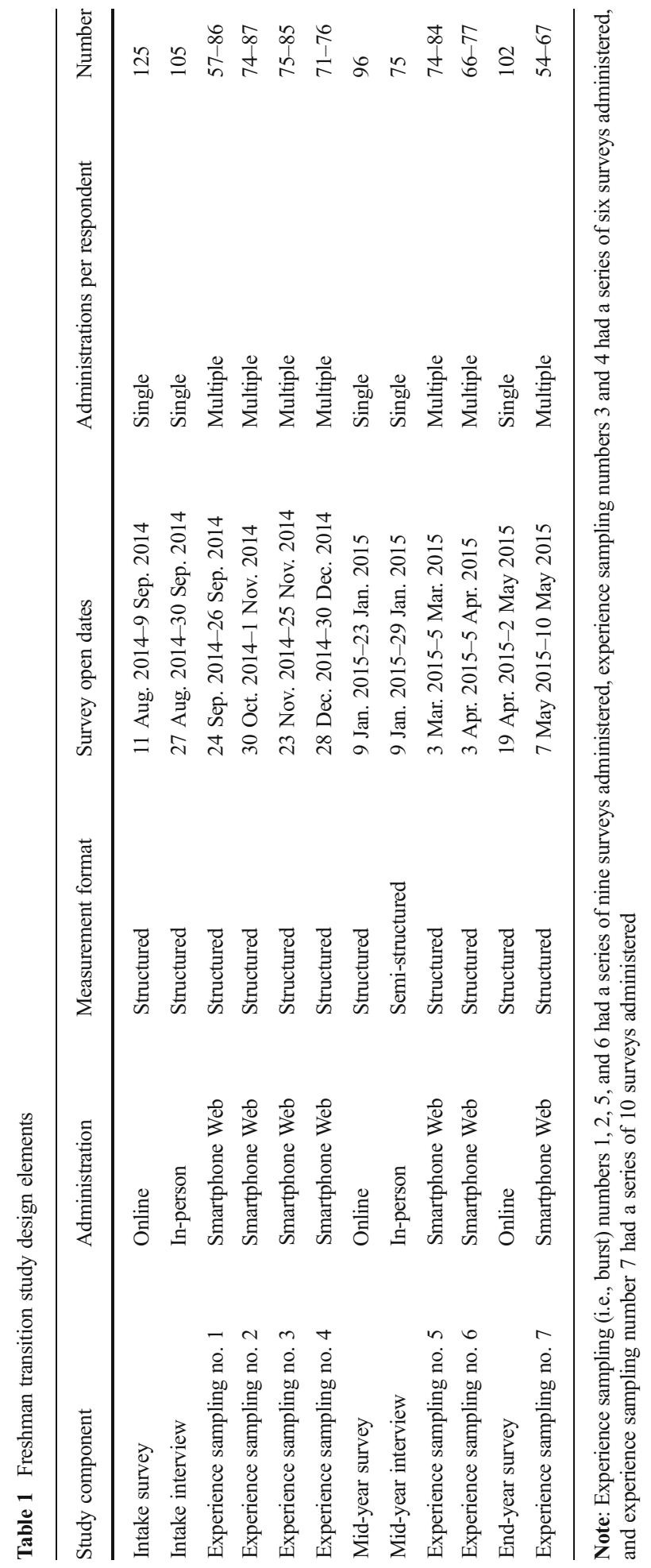


Table 2 Sample response rates across bursts

\begin{tabular}{llll}
\hline Burst & At least 1 survey (\%) & At least 2/3 of surveys (\%) & All surveys (\%) \\
\hline Burst $1(n=9)$; September & 83 & 71 & 30 \\
Burst 2 $(n=9)$; October & 83 & 71 & 37 \\
Burst $3(n=6)$; November & 81 & 74 & 52 \\
Burst $4(n=6)$; December & 75 & 66 & 42 \\
Burst $5(n=9)$; March & 76 & 72 & 48 \\
Burst $6(n=9)$; April & 76 & 65 & 33 \\
Burst $7(n=10)$; May & 70 & 55 & 26 \\
ES Total $(n=58)$ & 88 & 64 & 3 \\
\hline
\end{tabular}

Note: Response rates are based off of our starting sample of 105 students that completed the first in-person structured interview

expectations surrounding alcohol, alcohol use, and activities. In January, within the first couple weeks of spring semester, participants completed a second structured online survey that included most of the same questions that were covered at the baseline interview. The primary difference between these surveys was the distribution method, as the first survey was in person and the second survey was online. In April, a few weeks before the end of the academic year, participants completed a final, online structured survey, again with repeated questions from the beginning and middle of the year. In this paper, the information collected in the structured surveys at the beginning, middle, and end of the academic year serves as comparison points for data collected more often via experience sampling. While both the three-wave panel data described in this section and the cell phone data described in the next section were collected from structured surveys, we refer to the data from these three larger, in-depth surveys as coming from the "structured surveys."

\section{Burst Surveys Through Cell Phones}

A defining characteristic of the measurement-burst design is the repeated measurement over waves in combination with intensive data collection periods where data is collected multiple times in a short period of time, such as a day or several days. In our study, we collected seven bursts of experience sampling data over the course of the academic year (i.e., in September, October, November, December, March, April and May). Within each of these bursts, students participated in a number of short, repeated surveys for 3 days. ${ }^{6}$ Each day of a burst, participants received a text message with a link to a very short survey in the morning, afternoon, and evening for five of the seven bursts, and only in the morning and evening during the remaining two bursts. ${ }^{7}$ While some questions such as amount of sleep or daily ratings were asked only at certain

\footnotetext{
${ }^{6}$ Burst 7, given at the end of finals week in May, had 4 days instead of 3 . The survey given on the fourth day was intended to collect drinking and activity data that occurred on Saturday night but was not captured on the survey that went out Saturday night.

${ }^{7}$ We sent fewer surveys during the November and December bursts to reduce the burden put upon the students early in the study.
} 
times of the day, respondents were asked about their alcohol use and current activities on all cell phone surveys (see Appendix A).

We used the students' phone numbers and cell phone carriers that they reported on the online intake survey (approximately $93 \%$ reported having a smartphone) to send each respondent a personalized text message with instructions for how to join the cell phone portion of the project. ${ }^{8}$ Once a student joined, he or she received text messages with links to the survey. In order to complete the surveys, participants simply clicked on the link in the text message, which directed them to an online survey that automatically opened in their smartphone browser. Participants were instructed to answer the questions based on when they got the text, not when they filled out the survey. The window for filling out each survey was limited such that no two surveys could be completed at the same time. The majority of surveys were available to take for 5-6 h, although the evening survey always was available until 2:30 a.m. The mean percentage of participants who completed the survey within the first 15 min across all surveys was approximately $60 \%$ and ranged between 37 and $76 \%$ for all surveys excluding the very first one, where issues prevented a number of respondents from accessing the survey in a timely manner. As shown in Table 2, response rates decreased across the academic year and the lowest response rates were associated with the last cell phone burst, which was the first weekend in May after final exams were finished. ${ }^{9}$ We refer to this component as the "cell phone surveys." Respondents were given an incentive for participating in all aspects of this study. ${ }^{10}$

\section{Measures}

\section{Substantive Measures}

To examine activities across the school year, we used answers to one question that was asked on both the structured and cell phone surveys. On the cell phone surveys, we asked respondents, "What, primarily, were you doing when you received this link?" The options included productive activity, maintenance activity, leisure activity, idling, and an "other" category, and we focus on productive activities in this paper (see Appendix A). The option for productive activity read, "Productive activity for example, classwork, homework, structured extracurricular activities, work for pay, and religious activities." We asked the same question on the structured surveys, except that because

\footnotetext{
${ }^{8}$ We provided an email option for participants who either did not have a smartphone or preferred not to use it for the study $(n=9)$. The emails and texts included the same link to the online survey.

${ }^{9}$ Our results would not be affected if respondents did not fill out the survey immediately as we were interested in the broader patterns across the day and school year. Some cell phone questions were known quantities (e.g., amount of sleep) that would not be affected by the timing of the survey. The situational questions regarding what the respondents were doing when they were texted need only be a momentary assessment, and whether they were doing a particular activity at $10 \mathrm{a} . \mathrm{m}$. or 11:30 a.m. was not of interest to us. Only 16 of the 58 cell phone surveys had greater than $10 \%$ of respondents filling them out in the last $3 \mathrm{~h}$ of availability ( 9 of these were morning surveys, suggesting they were sleeping or in class). On the other hand, there were eight surveys where everyone who filled out a survey had done so with time to spare.

${ }^{10}$ The total potential reimbursement was US\$119 over the academic year, which was added through the University accounting office to their college ID and could be used for food and other purchases around campus. Of this amount, US\$61 could be earned for completing all of the larger surveys and interviews and US\$58 could be earned for completing the cell phone surveys.
} 
they were completing the questionnaire at different times across a few weeks, we asked them to answer based on their activities the prior evening at 7 p.m. For each structured and cell phone survey, respondents were coded " 1 " if they reported being engaged in a productive activity, and " 0 " if they reported engaging in any other activity type.

The measure of college drinking was coded "1" when it was determined that a respondent drank since the last survey they completed and a " 0 " when it was determined that they had not drank since the last survey they completed. There were different ways of determining whether drinking had occurred since the last survey. In some cases, it was the first survey of a new burst and the drinking occurred at some point since the last survey of the previous burst (see the drinking contingency question, Appendix A). In other cases, they were drinking when they filled out the survey or missed a night survey and reported a new drinking event the next morning (primary drinking question, Appendix A). When a respondent affirmatively reported drinking, we checked the previous survey responses by that respondent to be sure a report of drinking was not already recorded. This measure captures when they reported drinking and not necessarily when the drinking occurred.

\section{Control Variables}

In addition to the productive activity and drinking measures, all models included measures of time. The inclusion of time was necessary, yet the intra-day data collection posed unique problems. Specifically, we could not use the age of respondent because this did not change within the day. We also could not use day because there were multiple collection points within the day. To adequately capture time, we divided every day into three time points to reflect our morning, afternoon, and evening surveys. The first time point is time 3, which represents the evening our first structured survey went online. All cell phone and structured surveys after time 3 are coded by determining the number of days between the surveys and multiplying by 3, then adding any within day time points necessary. The first cell phone survey occurred at time 133 (24 Sep. 2014) and the last cell phone survey occurred at time 817 (10 May 2015). To illustrate, the first day of cell phone surveys were coded as time 133-135 and the first burst was coded 133-141 (i.e., 3 days long $\times 3$ surveys a day $=9$ time points in burst 1 ). For the analyses that follow, time was mean-centered, and these centered values were then squared and cubed. The level one data file consists of each time point for each person and contains data if a survey was filled out and was left missing when a survey was skipped.

In two of our productivity models, we included three dummy variables to control for when the survey was sent to respondents. In particular, we controlled for weekend surveys by including a measure that was coded " 1 " when it was a Friday survey and another measure that was coded "1" when it was a Saturday survey. Finally, we included a dummy variable that was coded " 1 " when the survey was sent out in the evening ( 1 = evening survey).

\section{Data Structure and Analysis}

The survey time points within each respondent created issues with dependence. To correct for this, we used multilevel modeling and Stata SE 14. To answer our research 
questions, we ran both two-level and three-level models. For the two-level models, we nested the survey time points within each respondent. For the three-level model, we nested the survey time points (level 1) in person-bursts (level 2), which were nested within the individual survey respondents (level 3). Our burst-level identifiers were created by taking the four-digit study IDs that were assigned to respondents, multiplying them by 100 , and then adding the burst number to the product. This coding allowed each of our respondents to be nested uniquely in each burst (i.e., person-bursts). Overall, we had over 4000 data points nested within 618 person-bursts, which were nested within 100 college freshmen. Table 3 presents the within-person, level-one time descriptives, in addition to between-person burst- and between-person individual-level descriptives for all of our measures.

\section{Results}

\section{Changes in Productive Activities}

To determine whether productive activities declined across the school year, we ran a series of multilevel logistic regression models. We began with a three-level logistic regression model that used the cell phone data, where productive activity was the dependent variable and time (centered), time squared, and time cubed were the independent variables at level one. Next, we entered two control variables for surveys

Table 3 Descriptives

\begin{tabular}{|c|c|c|c|c|c|c|}
\hline & \multicolumn{3}{|l|}{ Mean } & \multicolumn{3}{|l|}{ Range } \\
\hline & Time & Burst $^{\mathrm{a}}$ & Individual $^{\mathrm{a}}$ & Time & Burst $^{\mathrm{a}}$ & Individual $^{\mathrm{a}}$ \\
\hline \multicolumn{7}{|l|}{ SUBSTANTIVE } \\
\hline Drinking in college (year/n) & $\begin{array}{l}.10 \\
(.30)\end{array}$ & $\begin{array}{l}.12 \\
(.03)\end{array}$ & $\begin{array}{l}.10 \\
(.10)\end{array}$ & $0-1$ & $.07-.16$ & $0-.59$ \\
\hline Productive activity, cell phone & $\begin{array}{l}.30 \\
(.46)\end{array}$ & $\begin{array}{l}.31 \\
(.26)\end{array}$ & $\begin{array}{l}.33 \\
(.18)\end{array}$ & $0-1$ & $0-1$ & $0-1$ \\
\hline Productive activity, structured & $\begin{array}{l}.29 \\
(.45)\end{array}$ & - & $\begin{array}{l}.31 \\
(.34)\end{array}$ & $0-1$ & - & $0-1$ \\
\hline \multicolumn{7}{|l|}{ STRUCTURAL } \\
\hline Time & & - & - & $-348.72-335.28$ & - & - \\
\hline Time squared & & - & - & & - & - \\
\hline Time cubed & & - & - & & - & - \\
\hline Evening & $\begin{array}{l}.36 \\
(.45)\end{array}$ & $\begin{array}{l}.74 \\
(.37)\end{array}$ & $\begin{array}{l}.74 \\
(.27)\end{array}$ & $0-1$ & $0-1$ & $0-1$ \\
\hline Friday & $\begin{array}{l}.20 \\
(.40)\end{array}$ & $\begin{array}{l}.46 \\
(.46)\end{array}$ & $\begin{array}{l}.73 \\
(.29)\end{array}$ & $0-1$ & $0-1$ & $0-1$ \\
\hline Saturday & $\begin{array}{l}.14 \\
(.35)\end{array}$ & $\begin{array}{l}.32 \\
(.44)\end{array}$ & $\begin{array}{l}.67 \\
(.33)\end{array}$ & $0-1$ & $0-1$ & $0-1$ \\
\hline
\end{tabular}

Standard deviations in parentheses

${ }^{\text {a }}$ Burst and individual are between-person values 
that went out on a Friday or a Saturday and one for surveys that went out in the evening at level one.

The results from both of these analyses (see Fig. 1) suggested that students' participation in productive activities quickly declined between September and October, and the decline is noticeable within the first burst (i.e., 133-141). The probability of being engaged in a productive activity, such as work or structured activities, drops from about .48 down to about .31 in November. Although we do not have burst data at the beginning of the second semester, it appears that students had a higher probability of being engaged in a productive activity in the spring semester (about .42) than at the end of fall semester. They were never as productive as they were when they began fall semester, however. The last burst started on Thursday of finals week, which likely explains the low probability of being engaged in a productive activity during that burst.

We also ran a two-level fixed effects logistic regression model using the cell phone data. The respondent's report of being engaged in a productive activity was the dependent variable and time (centered), time squared, time cubed, and whether it was a Friday, Saturday, or evening survey were the independent variables at level one. In fixed effects models, all differences between level two units are removed and thus our estimates are for within-person change. The results, presented in Fig. 2, show the same general pattern as the results from Fig. 1. The primary difference is that the withinperson probabilities were higher. Specifically, in September, March, and April the

\section{Productive Activity Predicted Probabilities}

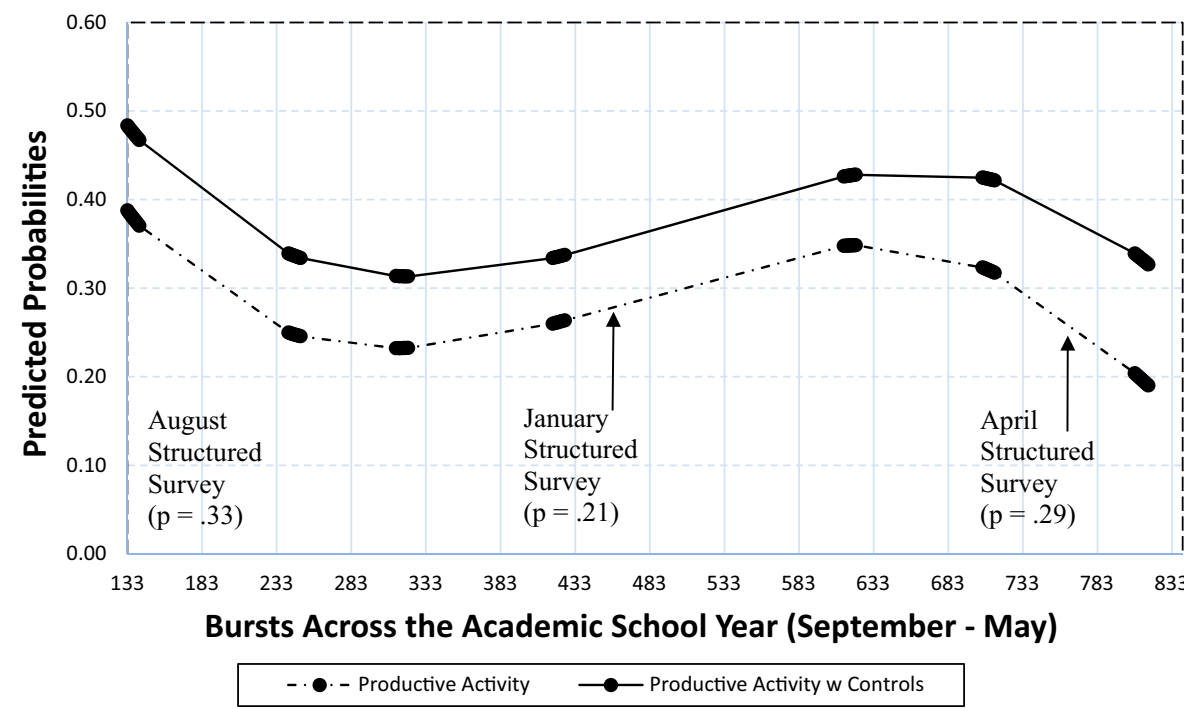

Fig. 1 Predicted probabilities of being in a productive activity over time from three-level logistic regression models. Results from the cell phone surveys $(n=100)$ were based on a three-level logistic regression model using Stata SE 14, with survey time points nested within bursts, nested within the individual survey respondents. The model without controls included only time, time squared, and time cubed and the model with controls also included whether it was a Friday survey, a Saturday survey, or an evening survey. The results from the structured surveys ( $n=129$ respondents) were based on a two-level fixed effects model that included only time and time squared. All independent variables were person-centered. The first time point was 133 in September and the last time point was 817 in May 


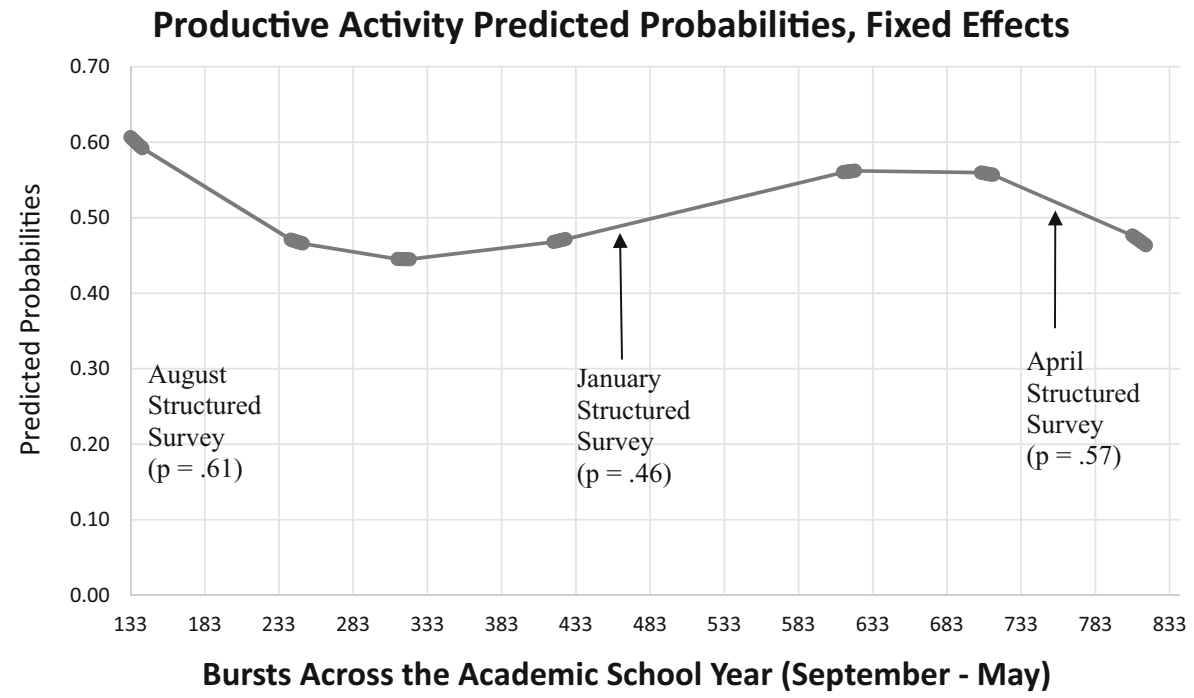

Fig. 2 Predicted probabilities of being in a productive activity over time from two-level fixed-effects logistic regression models. Results from the cell phone surveys ( $n=100$ respondents) were based on a two-level fixedeffects logistic regression model using Stata SE 14, with survey time points nested within the individual survey respondents. The model included time, time squared, time cubed, whether it was a Friday survey, a Saturday survey, or an evening survey. The results from the structured surveys ( $n=129$ respondents) were based on a two-level fixed effects model that included only time and time squared. All independent variables were person-centered. The first time point was 133 in September and the last time point was 817 in May

probabilities exceed .5 and approach .6. The baseline probability of .5 was never exceeded in the total effects model.

\section{Comparability of Productivity Estimates}

The next research question we addressed was about the comparability of the estimates between the structured and cell phone surveys. To examine this, we first ran a two-level logistic regression model (waves nested in students) using the three waves of the panel data from the structured surveys. The respondent's report of being engaged in a productive activity was the dependent variable and time and time squared were the independent variables at level one. These estimates, presented in Fig. 1, were statistically lower than the estimates from the cell phone surveys $(p=.033) .{ }^{11}$ We then ran a two-level fixed-effects logistic regression model that included time and time squared. These estimates from the structured surveys, presented in Fig. 2, are not statistically different than the fixed-effects estimates from the cell phone surveys $(p>.50)$. This means that the estimates between the two data sources were similar when controlling for all between-person differences.

There are at least four reasons why the total effects estimates between the two data sources would be different. First, the structured survey analysis was a two-level model and the cell phone survey analysis was a three-level model that had significant burstlevel variation. Second, the three data points were not sufficient for modeling time

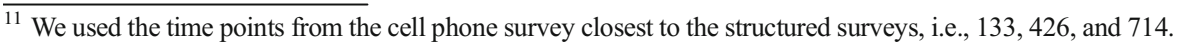


cubed. Third, the sample from the structured surveys was larger than the sample from the cell phone surveys. Finally, the respondents of the structured survey were asked what they were doing at 7 p.m. the night before.

To examine some of these possibilities, we ran additional models to determine whether we could get comparable results if we reduced the sample down to our cell phone sample of respondents or if we examined only the evening cell phone surveys. When we reduced the sample of structured survey respondents to match the cell phone survey respondents, the predicted probabilities were still significantly different from each other $(p=.03)$. On the other hand, when we reduced our cell phone sample to only evenings, there were no statistically significant differences between our predicted probabilities. In total, these findings suggest that engaging in productive activities may vary within the day, but is similar at the same time of the day across days of the week.

\section{College Drinking}

Turning to our research questions regarding drinking, we first examined whether students increased their drinking over time such that it could be modeled with a linear model. Figure 3 presents the results from two different two-level hierarchical logistic regression models, where each cell phone survey time point was nested in the respondents (the burst-level variation was not significant). One model is a fixed-effects logistic model, limited to within-individual change, and the other is a mixed-effects logistic model. While the time-squared term was not significant, the time-cubed term was significant. This indicates that college drinking did not occur as a linear function of

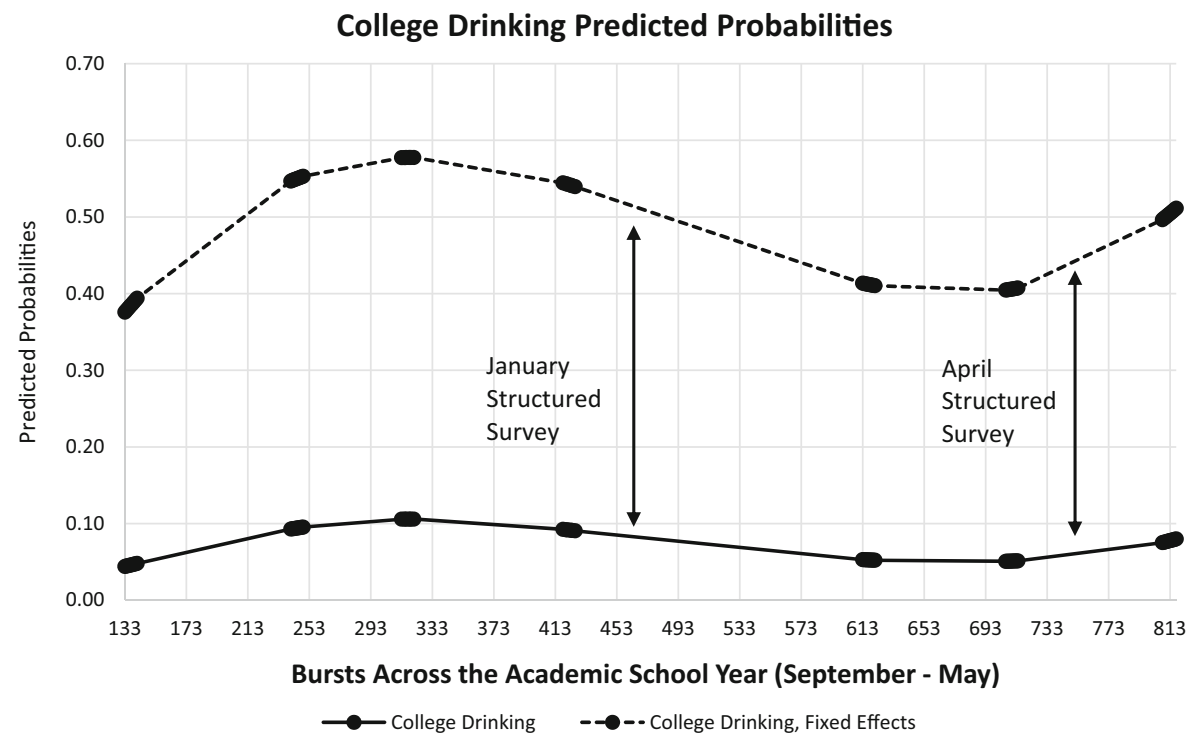

Fig. 3 Predicted probabilities of college drinking over time from multilevel logistic regression models. Results from the college drinking model were based on a two-level hierarchical logistic model, with survey time points nested within the individual survey respondents. The results for the fixed-effects model were based on a two-level logistic regression model, with survey time points nested within the individual survey respondents. Both models included time, time squared, and time cubed, which were person-centered 
time. The results presented in Fig. 3 shows increase in drinking at the beginning of the semester, which peaked in November and declined through December and reaching the lowest points in March and April.

Finally, we collected detailed information on college norms and drinking on the structured surveys, which could not have been collected through the quick cell phone surveys. As such, different questions about drinking were asked on the structured surveys. Our final research question was whether both sources produced similar estimates with regard to the percentage of students who had drank, across multiple sources with different ways of collecting information about drinking. This is important to determine given the rapid spike in college drinking that occurred at the beginning of the year (see Fig. 3).

Table 4 reports the percentage of college freshmen that live on campus who reported drinking based on different instruments and survey questions. The first column presents the percentage of college students who reported ever drinking more than a few sips. These percentages are based off of the number of respondents who filled out each survey. In August as college was starting, $57 \%$ of respondents reported having ever drank. When we asked respondents in January the same question, $76 \%$ of respondents had reported drinking, and that remained unchanged in April. Using the structured surveys, we would have known that the percentage of college students drinking increased by almost $20 \%$ between the end of August and the beginning of January.

The second column of Table 4 contains the percentages of respondents who ever drank based off of the cell phone survey question asking if they drank since the last survey, where non-drinkers who reported drinking were then coded as an ever drinker. The percentage of college students who ever drank had a $7 \%$ increase from September to October, with another $3 \%$ increase between October and November. While the cell phone survey percentage converges with the online structured survey percentage in January, we can see that most of the increase occurred between the end of August and

Table 4 Reported ever and college drinking across survey methods

\begin{tabular}{|c|c|c|c|c|c|}
\hline $\begin{array}{l}\text { Month of } \\
\text { survey }\end{array}$ & Burst & $\begin{array}{l}\text { Percentage ever had a } \\
\text { drink at the structured } \\
\text { survey points } \\
\text { Ever drank }\end{array}$ & $\begin{array}{l}\text { Percentage ever } \\
\text { drinking from cell } \\
\text { phone surveys }\end{array}$ & $\begin{array}{l}\text { Percentage college } \\
\text { drinking across all } \\
\text { survey types } \\
\text { Drank in college }\end{array}$ & $\begin{array}{l}\text { Percentage college } \\
\text { drinking in fall and in } \\
\text { spring semester }\end{array}$ \\
\hline August & & $57 \%$ & & & \\
\hline September & 1 & & $63 \%$ & $44 \%$ & \\
\hline October & 2 & & $70 \%$ & $64 \%$ & \\
\hline November & 3 & & $73 \%$ & $71 \%$ & \\
\hline December & 4 & & $75 \%$ & $73 \%$ & \\
\hline January & & $76 \%$ & & $74 \%$ & $64 \%$ \\
\hline February & & No surveys & No surveys & No surveys & No surveys \\
\hline March & 5 & & $76 \%$ & $74 \%$ & \\
\hline April & 6 & $76 \%$ & & $74 \%$ & $82 \%$ \\
\hline May & 7 & & $79 \%$ & $78 \%$ & \\
\hline
\end{tabular}

The italicized months with no burst numbers represent the responses from the three-wave panel survey component. The months with a burst number are averages based off of the cell phone surveys 
the end of October. In fact, for college students who had never drank upon entering college, $18 \%$ of them who then did drink did it by December and only another $4 \%$ ever drank before May.

The last two columns of Table 4 are based on drinking after the start of college. In our September cell phone survey, we estimated that $44 \%$ of the college students had drank since the first day of school. By October, this number had reached $64 \%$, a $20 \%$ increase in 1 month. The percentage of college drinkers increased by another $7 \%$ between October and November. Overall, from this column it is evident that the onset of drinking occurred largely by the November survey. There was little change between December and April, and then a jump of $4 \%$ at the end of May. The final column presents the percentages from the January and April online structured surveys. We asked whether a respondent drank over fall semester on the January survey and whether they drank spring semester on the April survey. These numbers are the most inconsistent, and it is possible that the $64 \%$ in January and the $82 \%$ in April reflects recall issues given the semester-wide window for reporting drinking.

Overall, the results from Table 4 and Fig. 3 suggest that our understanding of college drinking across the semester would have been limited had we relied on the structured survey data. The extent and timing of the peak would have been missed in the January survey. Similarly, the valley that occurred before the April survey would have been missed, although in both cases the increase and decrease would have been evident. Additionally, we would not know that the predicted probability of drinking was on the decline by the January survey and was increasing again by the April survey.

\section{Discussion and Conclusion}

The purpose of our study was twofold. First, we were interested in capturing potential changes in both productive activities (e.g., working, structured activities) and drinking over the course of the freshman year. Second, we were interested in exploring the comparability of estimates between the two design components (i.e., structured surveys and cell phone surveys) employed as part of our hybrid methodological approach. Although this study was based on data from a pilot study, our findings have both substantive and methodological implications for future research.

Generally speaking, the predicted probability of being engaged in a productive activity decreased over the course of the fall semester and then rose again in the spring semester before dropping at the end of the year (during/after finals week). With regard to drinking, the pattern is nearly reversed. The predicted probability of drinking rises quickly at the beginning of the fall semester and then dips at the end of the fall semester until it rises again near the end of the spring semester. Collectively, these results suggest that a lot of changes are taking place in the first few months of the college transition making the first semester a particularly important one. The uptick in reported drinking is not necessarily a surprise as previous research has indicated an increase in drinking, particularly binge drinking, following college matriculation [29]. Further research on college drinking suggests that there is a strong association between normative beliefs about alcohol and reported use [10, 30, 31]. Additional data from our structured surveys shows an increase in normative beliefs between August and January; thus, it is likely 
that attitudes and behaviors are changing simultaneously. More research is needed to examine potential co-occurring changes during this time period.

With regard to productive activity, students may be exercising their newfound independence and thus productive activities may be quickly replaced by leisure and idling activities, such as sleeping in, spending time with friends, binging on Netflix, or skipping class. The slight increase in productive activities during the spring semester could potentially be explained as being a result of an unsuccessful fall semester or an increase in work responsibilities during spring semester before these on-campus freshmen leave for the summer. More research is needed to explore how college students, and especially transitioning freshmen, spend their time.

An advantage of our hybrid design is that we were able to discover that not only does the first semester represent a period of significant change, but the first couple months may be particularly important with regard to college drinking patterns. The examination of students who have ever drank and those who drank after starting college both show large increases within the first month or two of fall semester. By the time of the January online survey, most of the students who were going to drink in their freshmen year already had begun drinking. This finding is of practical importance for alcohol prevention programming efforts on campuses across the country. Specifically, programming which is front-heavy with regard to intervention and the distribution of resources may be most effective.

Further, these findings clearly demonstrate the utility of data collected from burst designs $[23,25]$. The beginning, middle, and end of the year surveys were insufficient for capturing exactly when developmental changes were occurring. In fact, our burst design would have benefited from even more frequent bursts during the first 2 to 3 months of the semester. It may be that weekly or bi-weekly collection is needed to adequately model the intra-individual change that was occurring in our sample with regard to drinking.

Methodologically, for the productive activity measure, we were able to compare the estimates between the structured and cell phone surveys. Fixed-effect models that produced estimates of within-individual change across the year were not statistically different between the two sources. We did find significant differences between the structured and cell phone data when we examined the total effect of doing something productive. This difference disappeared once we used only evening data from the cell phone surveys. Overall, the findings suggest that there is intra-day variability in terms of spending time engaging in a productive activity, although patterns across the days of the week are more stable (e.g., rarely engaging in a productive activity in the evening).

Overall, there are advantages to the hybrid design, particularly the incorporation of burst designs using ESM. First, researchers can have a smaller sample that has enough power for different types of analyses with enough data points on each respondent, and ESM using smartphones can increase the amount of data collected without adding a lot of cost to the project. Second, including a larger, structured survey component allows researchers to collect information on correlates of the behavior of interest, which reduces the information that needs to be collected through the other study components, such as the ESM. Third, including the burst design allows for the examination of intraday changes in attitudes and behaviors that is not possible with a traditional panel design, in addition to rapid changes in a short period of time. 


\section{Limitations and Methodological Considerations}

While our study benefited from the burst design, there were a number of challenges to our collection efforts. We briefly review some of these challenges and provide recommendations for others considering similar designs. First, we wanted to retain as many participants in the sample as possible and, as a result, we allowed participants to fill out whichever surveys they were able to fill out and remain in the study. This flexibility caused response rates to vary across all data collection methods, especially text surveys. Additionally, it also created a large amount of missing data for respondents who missed many surveys. The amount of missing data was higher than that found in other studies using burst designs with in-person collection methods (e.g., [27]). Respondents could skip questions with our cell phone surveys that they would not have been able to skip as easily if being interviewed by a researcher, such as which friends they were with at the time. Researchers contemplating similar designs might consider playing around with the length of burst periods and the number of surveys within them. Our highest response rate was for one of the bursts with fewer surveys (see Table 2). Thus, reducing the burden within a burst period may boost response rates. Another way to boost response rates might be to combine per survey incentives (which we used) with bonuses for completing a certain percentage of available surveys (e.g., an extra US\$2-3 awarded for completing at least $90 \%$ of surveys in a given burst period). More research is needed to determine how many questions/how much time college students are willing to spend answering survey questions multiple times a day across multiple days.

In an attempt to regain some of the missing drinking data, we asked respondents if they drank since the last survey and included an option for those who did not fill out the last survey. ${ }^{12}$ If they checked this option, they were skipped to a drinking question that asked them structured questions about when they drank last (see Appendix A). This was useful especially on weekends when respondents were more likely to miss an evening survey and report having drank since the last survey the next morning. On the other hand, this created complex coding issues. This was because a respondent could have reported drinking, skipped surveys, and then was prompted to report when they drank last. To be sure each report of drinking was a newly reported drinking event, all reports of drinking through the backup drinking question that did not fall on the first survey of a new burst were manually checked by the first author and a graduate assistant, which was labor intensive. Researchers interested in capturing behavior through a burst design must design questions such that respondents do not doublereport behaviors, although they may not always remember reporting a behavior.

Along with missing data and survey structure, we also discovered unique challenges posed by within-day data collection. Static within-day behavior, such as the amount of sleep a respondent received, was the easiest to collect. All respondents were able to report the number of hours they slept (or did not sleep) on every morning survey, as long as they completed the survey. Dynamic within-day behavior was much more

\footnotetext{
12 The yes/no drinking question was sufficient for capturing the onset of drinking and was simple for the purposes of our pilot study using EMAs. This measurement is limited, however, in that it does not capture the complexity of drinking behavior such as the quantity of drinks consumed or the duration of the drinking episode.
} 
difficult to determine when it took place. For example, respondents could report that they drank since the last survey on the morning survey. Even if they filled out the previous evening survey, it was sometimes difficult to determine whether they started drinking after the evening survey or if they were drinking before the morning survey. The drinking events that were the hardest to determine were associated with respondents who reported drinking on all of the within-day surveys and who also had missed the evening before. Although this did not occur often, we determined drinking behaviors based on the timing of the night and morning surveys and the specific surveys and the responses to them that each respondent completed.

Overall, researchers interested in employing burst designs need to find ways of measuring concepts that are not burdensome to the respondent and that map onto more complex measurements. For example, we were interested in depression, but we did not think respondents would fill out a depression scale multiple times a day, or even once daily. As a result, we simplified this concept to two general measures of how respondents viewed their day (i.e., how would you rate your day, how productive were you today). More research is needed to determine non-invasive questions that will capture complex phenomena. Additionally, the test-re-test reliability of measures needs to be examined across multiple collection points $[25,26]$.

While our burst design created many data complexities that needed attention, it was worth the effort. We collected cell phone data almost monthly in addition to three larger surveys at the beginning, middle, and end of the year. Our findings show that the three larger surveys would have been insufficient to examine the developmental trends that interested us. In particular, activities such as doing something productive would have been subject to measurement error leading to under-estimation in the predicted probabilities, except in the fixed-effects models. Additionally, the findings about the quickness of the onset of drinking would have been lost, in addition to the overall trend that was best modeled with a cubed term. Based on our findings, researchers interested in using a burst design to study the onset of college drinking would be best served by many data collection points within the first few months of the semester.

In this paper, we examined college students' activities and drinking because we expected that engaging in productive activities and not drinking would be part of a healthy transition to college. Based on our findings, prevention and intervention efforts intended to ensure a healthy transition from being a dependent adolescent to being an independent and successful young adult in college should be more heavily focused on fall than spring semester. There are many transitions and changes that criminologists and criminal justice researchers could study, however, through the use of a burst design. Some examples include the intra-day mood fluctuations of domestic batterers, the transition of released offenders from prison to successful re-entry into the community, the after-school activities of at-risk adolescents, the cravings and/or relapses of drug and alcohol abusers, and public opinion of criminal justice issues. Programs and interventions could be better informed because the burst design can pinpoint peaks and valleys in behavior, thus allowing for better timing of delivery and effective utilization of resources. Moreover, the widespread use of smart devices such as cell phones and tablets can help reduce the resources required to do these kinds of studies. In conclusion, we argue that criminology and criminal justice researchers who are interested in transitions would benefit from data collection through a burst design. 


\section{References}

1. Christie, D., \& Viner, R. (2005). Adolescent development. BMJ, 330(7486), 301-304.

2. Crocetti, E., Rubini, M., Branje, S., Koot, H. M., \& Meeus, W. (2015). Self-Concept Clarity in Adolescents and Parents: A Six-Wave Longitudinal and Multi-Informant Study on Development and Intergenerational Transmission. Journal of personality.

3. Dahl, R. E. (2004). Adolescent brain development: a period of vulnerabilities and opportunities. Keynote address. Annals of the New York Academy of Sciences, 1021(1), 1-22.

4. Fischer, K. W., \& Rose, S. P. (1998). Growth cycles of brain and mind. Educational Leadership, 56, 5660 .

5. Nottelmann, E. D., Susman, E. J., Dorn, L. D., Inoff-Germain, G., Loriaux, D. L., Cutler, G. B., \& Chrousos, G. P. (1987). Developmental processes in early adolescence: relations among chronologic age, pubertal stage, height, weight, and serum levels of gonadotropins, sex steroids, and adrenal androgens. Journal of Adolescent Health Care, 8(3), 246-260.

6. Sampson, R. J., \& Laub, J. H. (2005). A life-course view of the development of crime. Annals of the American Academy of Political and Social Science, 602, 12-45.

7. Hill, N. E., \& Wang, M. T. (2015). From middle school to college: developing aspirations, promoting engagement, and indirect pathways from parenting to post high school enrollment. Developmental Psychology, 51(2), 224.

8. Keijsers, L., \& Poulin, F. (2013). Developmental changes in parent-child communication throughout adolescence. Developmental Psychology, 49(12), 2301.

9. Nguyen, A., Taylor, J., \& Bradley, S. (2003). Relative pay and job satisfaction: Some new evidence.

10. Borsari, B., \& Carey, K. B. (2003). Descriptive and injunctive norms in college drinking: a meta-analytic integration. Journal of Studies on Alcohol, 64(3), 331.

11. Champion, D. A., Lewis, T. F., \& Myers, J. E. (2015). College student alcohol use and abuse: social norms, health beliefs, and selected socio-demographic variables as explanatory factors. Journal of Alcohol Drug Education, 59(1), 57-82.

12. Napper, L. E., Hummer, J. F., Chithambo, T. P., \& LaBrie, J. W. (2015). Perceived parent and peer marijuana norms: the moderating effect of parental monitoring during college. Prevention Science, 16(3), 364-373.

13. Rimal, R. N., \& Mollen, S. (2013). The role of issue familiarity and social norms: findings on new college students' alcohol use intentions. Journal of Public Health Research, 2(1), 31-37.

14. Clark, D. B., Thatcher, D. L., \& Tapert, S. F. (2008). Alcohol, psychological dysregulation, and adolescent brain development. Alcoholism: Clinical and Experimental Research, 32(3), 375-385.

15. Lebel, C., \& Beaulieu, C. (2011). Longitudinal development of human brain wiring continues from childhood into adulthood. The Journal of Neuroscience, 31(30), 10937-10947.

16. Substance Abuse and Mental Health Services Administration, 2013 National Survey on Drug Use and Health (NSDUH). Table 6.88B-Alcohol use in the past month among persons aged 18 to 22, by college enrollment status and demographic characteristics: Percentages, 2012 and 2013. http://www.samhsa.gov/ data/sites/default/files/NSDUH-DetTabsPDFWHTML2013/Web/HTML/NSDUHDetTabsSect6peTabs55to107-2013.htm\#tab6.88b

17. Osgood, D. W., Wilson, J. K., O’Malley, P. M., Bachman, J. G., \& Johnston, L. D. (1996). Routine activities and individual deviant behavior. American Sociological Review, 61, 635-655.

18. Mahoney, J. L., \& Stattin, H. (2000). Leisure activities and adolescent antisocial behavior: the role of structure and social context. Journal of Adolescence, 23, 113-127.

19. Maimon, D., \& Browning, C. R. (2010). Unstructured socializing, collective efficacy and violent behavior: integrating individual and structural level explanations of crime. Criminology, 48, 443-474.

20. Larson, R. W., Richards, M. H., Moneta, G., Holmbeck, G., \& Duckett, E. (1996). Changes in adolescents' daily interactions with their families from ages 10 to 18: disengagement and transformation. Developmental Psychology, 32(4), 744.

21. Larson, R. W., Richards, M. H., Sims, B., \& Dworkin, J. (2001). How urban African American young adolescents spend their time: time budgets for locations, activities, and companionship. American Journal of Community Psychology, 29(4), 565-597.

22. Csikszentmihalyi, M., \& Larson, R. (1987). Validity and reliability of the Experience-Sampling Method. The Journal of Nervous and Mental Disease, 175(9), 526-536.

23. Nesselroade, J. R. (1991). The warp and the woof of the developmental fabric. In R. M. Downs, L. S. Liben, D. S. Palermo, R. M. Downs, L. S. Liben, \& D. S. Palermo (Eds.), Visions of aesthetics, the 
environment \& development: the legacy of Joachim F. Wohlwill (pp. 213-240). Hillsdale, NJ, England: Lawrence Erlbaum Associates, Inc.

24. Affleck, G., Zautra, A., Tennen, H., \& Armeli, S. (1999). Multilevel daily process designs for consulting and clinical psychology: a preface for the perplexed. Journal of Consulting and Clinical Psychology, $67(5), 746$.

25. Sliwinski, M. J. (2008). Measurement-burst designs for social health research. Social and Personality Psychology Compass, 2(1), 245-261.

26. Hedeker, D., \& Mermelstein, R. J. (2007). Mixed-effects regression models with heterogeneous variance: analyzing ecological momentary assessment (EMA) data of smoking. Modeling contextual effects in longitudinal studies, 183-206.

27. Patrick, M. E., Maggs, J. L., \& Lefkowitz, E. S. (2015). Daily associations between drinking and sex among college students: a longitudinal measurement burst design. Journal of Research on Adolescence, 25(2), 377-386.

28. Cullum, J., O’Grady, M., Armeli, S., \& Tennen, H. (2012). Change and stability in active and passive social influence dynamics during natural drinking events: a longitudinal measurement-burst study. Journal of Social and Clinical Psychology, 31(1), 51.

29. Johnston, L. D., O’Malley, P. M., Bachman, J. G., \& Schulenberg, J. E. (2012). Monitoring the future national survey results on drug use, 1975-2011: volume II, college students and adults ages 19-50. Ann Arbor: Institute for Social Research, The University of Michigan.

30. Clinkinbeard, S. S., \& Rhodes, T. N. (2014). Propensity, social ties, friend behavior, and heavy drinking among college students. Journal of Child \& Adolescent Substance Abuse, 23(6), 362-374.

31. Perkins, H. W. (2002). Social norms and the prevention of alcohol misuse in collegiate contexts. Journal of Studies on Alcohol. Supplement, 14, 164-172. 